\title{
STRATEGI LITERASI DALAM PEMBELAJARAN MATEMATIKA PADA ERA INDUSTRI 4.0
}

\author{
Baiduri \\ Universitas Muhammadiyah Malang \\ baiduriumm@gmail.com
}

\begin{abstract}
ABSTRAK
Setiap siswa atau manusia ingin sukses, baik secara akademik maupun dalam kehidupan kesehariannya. Kehadiran industri 4.0 membawah perubahan yang sangat cepat, tidak hanya dalam dunia manufaktur dan produksi tetapi juga dalam skill yang dibutuhkan di dunia kerja. Kecapakan yang sangat penting dan mendasar untuk ini adalah kecakapan bahasa dan kecakapan matematika. Kecakapan matematika meliputi kosakata dan notasi, ruang dan bentuk, numerasi, dan kuantitatif. Makna yang tersirat dalam kecakapan (literasi) matematika adalah kemampuan untuk mengajukan, merumuskan, dan memecahkan masalah intra dan ekstra matematika dengan bahasa yang dapat dimengerti oleh orang lain umumnya dan matematikawan pada khususnya. Berbagai strategi literasi dibahas secara teoritis dan implementasinya dalam pembelajaran matematika supaya dapat mahir secara matematis agar dapat mengambil keuntungan hadirnya era industri 4.0 atau era setelahnya.
\end{abstract}

Kata Kunci: strategi literasi, pembelajaran matematika, industri 4.0.

\begin{abstract}
Every student or human want success, either in their academic matter or daily life. The presence of Industry 4.0 carries the significant change, not only in manufacture and production industry, but also in skill demand in labour industry. The crucial and fundamental skills which are needed is the language skill and mathematic skill. The mathematic skill is included vocabulary and notation, space and shape, numeration, and quantitative. The implicit meaning of (well-literated) mathematic skill is the ability to propose, formulate, and solve the problem both internal and external mathematic issues with understandable language output by others, especially mathematician. There are varieties of literation strategy which has been theoreticallydiscussedand its implementation in mathematic learning in order to achieve mastery and gain the maximum advantages towards the presence of Industry Revolution 4.0 eraand after.
\end{abstract}

Keywords: literacy strategy, mathematic learning, industry 4.0. 


\section{Baiduri}

\section{PENDAHULUAN}

Kehadiran era industri 4.0 dengan komponen utamanya Cyber-Physical System (CPS), Internet of Things (IoT), Smart Factory (SF), dan Internet of Services (IoS) (Hermann dkk, 2015) berkomunikasi dan bekerjasama satu sama lain dengan manusia secara real time melalui web nirkabel (Marr, 2016) yang digunakan untuk meningkatkan otomatisasi, komunikasi dan penggunaan data secara real-time sehingga membantu produsen berinovasi lebih cepat (Moore, 2018) dan berakibat pada biaya operasional yang optimum. Martin (2017) menyatakan bahwa keuntungan Industri 4.0 yaitu (1) Optimization (Optimasi), (2) Customization (Penyesuaian), (3) Pushing Research (Mendorong Penelitian). Sedangkan tantangan yang dihadapi yaitu (1) Security (Keamanan), (2) Capital (Modal), (3) Employment (Ketenagakerjaan), dan (4) Privacy (Privasi/kerahasiaan).

Aspek ketenagakerjaan menjadi hal yang sangat serius. Boleh jadi jenis pekerjaan yang ada saat ini sudah tidak ada di masa yang akan datang, skill yang dibutuhkan dunia kerja masa depan boleh jadi berbeda dengan saat ini. Selain itu ketenagakerjaan sangat erat kaitannya dengan pendidikan dan pelatihan untuk menyiapkan skill yang diperlukan. Forum ekonomi dunia menyatakan ada sepuluh skill utama yang diperlukan dalam dunia kerjapada tahun 2020, yaitu: 1. Complex Problem Solving, 2. Critical Thinking, 3. Creativity, 4. People Management, 5. Coordinating with Others, 6. Emotional Intelligence, 7. Judgement and DecisionMaking, 8. Service Orientation, 9. Negotiation, 10. Cognitive Flexibility (World Economic Forum, 2016). Selain itu skill dalam menggunakan teknologi digital dalam pekerjaan menjadi sebuah keharusan. Mengisi kebutuhan baru bisnis dalam rangka menciptakan tenaga kerja, menghadapi tantangan sosial dan lingkungan global merupakan tantangan bagi generasi sekarang dan akan datang (BrownMartin, 2017; TFO, 2017). Sehingga perlu dipersiapkan generasi yang kuat untuk masa datang. Ajaran agama telah mengingatkan tentang pentingnya menyiapkan generasi yang kuat. "Dan hendaklah takut kepada Allah orang-orang yang seandainya meninggalkan dibelakang mereka anak-anak yang lemah, yang mereka khawatir terhadap (kesejahteraan) mereka. Oleh sebab itu, hendaklah mereka bertakwa kepada Allah dan hendaklah mereka mengucapkan perkataan yang 
benar." (QS. An Nisa: 9). Hal ini dipertegas hadits Rasûlullâh Shallallahu 'alaihi wa sallam,"Mukmin yang kuat lebih baik dan lebih dicintai Allah daripada Mukmin yang lemah.” (HR. Muslim).

Pendidikan merupakan salah satu instrumen yang dapat digunakan dalam mempersiapkan generasi yang tangguh. Ali bin Abi Thalib menyatakan bahwa "didiklah anakmu karena dia akan hidup di masa yang tidak sama dengan masa mu". Apakah skill-skill tersebut dapat diperoleh dari belajar matematika? Ketika pengetahuan dan ekonomi berkembang, orang lebih banyak bekerja dengan teknologi atau bekerja di lingkungan dimana matematika merupakan landasan. Pemecahan masalah, pemrosesan informasi, dan komunikasi menjadi persyaratan pekerjaan rutin. Literasi matematika diperlukan baik di tempat kerja maupun dalam kehidupan sehari-hari. Ini adalah salah satu kunci untuk mengatasi masyarakat yang berubah. Mengingat bahwa dunia sedang bergerak menuju ekonomi berbasis pengetahuan, kurangnya literasi matematika adalah masalah besar. Hal senada dikatakan oleh Mulyani bahwa pentingnya penguasaan matematika untuk mengelola ekonomi negara terlebih dalam menghadapi era revolusi industri 4.0. Karena peranan matematika sangat besar dalam memahami fenomena baru yang terlahir dari digital ekonomi secara luas. Jika bicara Indonesia ke depan selain language dan behavior, basic matematika luar biasa penting (Kumparan.com, 30 September 2018).

Ketika berbicara tentang matematika seolah-olah itu adalah entitas tunggal, tetapi sebenarnya matematika memiliki empat wajah yang disajikan kepada dunia: 1) Perhitungan, penalaran formal, dan pemecahan masalah. 2) Matematika sebagai cara untuk mengetahui. 3) Matematika sebagai media kreatif. 4) Aplikasi (Devlin, 2000). Sebagian besar pendidikan sekolah (dan universitas) berkonsentrasi pada wajah pertama dan membuat beberapa referensi ke wajah keempat, tetapi sedikit atau tidak sama sekali memperhatikan dua wajah lainnya. Ketika memasuki era industri 4.0, pendidikan matematika harus menampilkan keempat wajah. Laju perubahan sedemikian cepat saat ini tidak ada yang bisa memprediksi apa yang akan menjadi pengetahuan dan keterampilan paling penting untuk menjalani kehidupan, untuk memainkan peran sebagai warga negara, dan menjadi produktif dengan cara mereka sendiri. Wajah keempat, 


\section{Baiduri}

aplikasi matematika dalam kehidupan nyata merupakan fokus dari literasi matematika (De Lange, 2003). Literasi matematika sama pentingnya dengan kemahiran dalam membaca dan menulis (Ojose, 2011). “Tomorrow's illiterate will not be those who cannot read, but those who have not learned how to learn" (Toffler, 1970). Literasi Matematika merupakan keterampilan yang diperlukan untuk abad ke-21 (Atif, 2013). Makalah ini menguraikan secara teoritis tentang pengunaan literasi dalam pembelajaran matematika disertai dengan beberapa contoh.

\section{LITERASI MATEMATIKA}

Proses pengembangan keterampilan membaca cukup dikenal. Pertamatama kita belajar suara, lalu huruf, lalu bagaimana huruf dan suara membuat katakata. Selanjutnya kita belajar apa artinya semua itu dan bagaimana memahami bahasa tulisan kita. Keterampilan membaca (literacy skill) sangat penting di sekolah (dan dalam kehidupan), semakin kuat keterampilan membaca siswa, semakin besar peluang mereka untuk mencapai keberhasilan akademis. Akan tetapi sangat disayangkan proses menjadi mahir (literate) matematika kurang dikenal, padahal ini sama pentingnya bagi keberhasilan siswa. Sehingga literasi matematika merupakan literasi kedua yang mesti dikuasai siswa setelah literasi bahasa. Literasi matematika adalah topik yang banyak dibahas di sebagian besar negara, dengan berbagai istilah seperti numerasi, atau literasi kuantitatif, atau matheracy, atau sebagai bagian dari ethnomathematics, atau terkait dengan matematika dalam masyarakat (Vithal \& Bishop, 2006).

Matematika memiliki bahasa yang sangat spesifik dan tepat. Agar siswa dapat mahir secara matematis, mereka harus dapat berkomunikasi dengan jelas dalam bahasa itu dengan memahami kosakata, simbol, dan cara merumuskan argumen. Kosakata mungkin membingungkan karena kata-kata memiliki arti yang berbeda dalam konteks matematika dan non-matematika karena dua kata yang berbeda terdengar sama (misal, faktor, prima, kombinasi), atau karena lebih dari satu kata digunakan untuk menggambarkan konsep yang sama (gradien, kemiringan garis). Simbol dapat membingungkan karena terlihat mirip (misal, simbol pembagian dan akar kuadrat) atau karena representasi yang berbeda dapat 


\section{Strategi Literasi dalam Pembelajaran Matematika Pada Era Industri 4.0}

digunakan untuk menggambarkan proses yang sama (misal $\bullet$, *, dan $\times$ untuk perkalian) atau representasi yang sama untuk konsep yang berbeda (misal, $\Leftrightarrow$ untuk ekuivalen dalam persamaan dan biimplikasi dalam logika). Sehingga perlu pengajaran disiplin literasi, yang berpotensi untuk mendukung tingkat pembelajaran dan komunikasi siswa yang lebih tinggi (Fang \& Coatoam, 2013; Hynd-Shanahan, 2015; Shanahan, 2012; Shanahan \& Shanahan, 2014). Secara tradisional literasi merupakan kecapakan membaca dan menulis. Disiplin literasi didefinisikan sebagai pertemuan konten pengetahuan, pengalaman, dan keterampilan yang digabungkan dengan kemampuan membaca, menulis, mendengarkan, berbicara, berpikir kritis, dan tampil dengan cara yang bermakna dalam konteks bidang tertentu (Borsecnik \& Holzhuter, 2015). Akan tetapi relatif sedikit yang diketahui tentang bagaimana guru saat ini mengadopsi dan memberlakukan praktik literasi (Ippolito, Dobbs, \& Charner-Laird, 2017). Dalam pelaksanaan pembelajaraan matematika di kelas, literasi matematika secara harfiah adalah segalanya; komunikasi, diskusi, melihat grafik dan banyak hal lainnya dalam proses pembelajaran (Ippolito, Dobbs, \& Charner-Laird, 2017). Unesco (2004) menyatakan literasi sebagai kemampuan untuk mengidentifikasi, memahami, menafsirkan, membuat, berkomunikasi dan menghitung, menggunakan bahan cetak dan tertulis yang terkait dengan berbagai konteks. Literasi melibatkan pembelajaran yang memungkinkan individu untuk mencapai tujuan, untuk mengembangkan pengetahuan dan potensi, dan untuk berpartisipasi penuh dalam komunitas mereka dan masyarakat. Ini berarti literasi sebagai pengetahuan dan kompetensi dalam bidang tertentu.

Menurut Watson (2002), literasi matematika adalah keterampilan mendasar yang diperlukan seperti bahasa. Watson (2002) dan Steen, Turner, dan Burkhardt (2007) juga menyatakan bahwa literasi matematika adalah salah satu tujuan utama organisasi pengajaran di sekolah. Literasi matematika memberikan siswa kesadaran dan pemahaman tentang peran yang dimainkan matematika di dunia modern. Literasi matematika adalah subjek yang didorong oleh aplikasi matematika yang berhubungan dengan kehidupan. Ini memungkinkan peserta didik untuk mengembangkan kemampuan dan kepercayaan diri untuk berpikir secara numerik dan spasial untuk menafsirkan dan menganalisis secara kritis 


\section{Baiduri}

situasi sehari-hari dan untuk memecahkan masalah (Department of Education, 2003; OECD, 2006; Ojose, 2011). Storm, Catharines, Marseglia, dan Lapointe (2010) menyatakan bahwa literasi matematika (juga dikenal sebagai nemurasi) berarti: 1) memiliki kemampuan untuk menyelesaikan masalah, bernalar, dan menganalisis informasi; 2) kemampuan untuk menggunakan angka dalam membantu memecahkan masalah dunia nyata; 3) kemampuan untuk memahami "bahasa" matematika (misalnya "penjumlahan" berarti jawaban untuk penjumlahan, "selisih" berarti jawaban untuk pertanyaan pengurangan. Ini berarti literasi matematika dikaitkan dengan kemampuan menggunakan angka dan memahami bahasa matematika.

Gagasan literasi numerik atau matematika, sebagaimana didefinisikan di atas, bukanlah matematika canggih seperti kalkulus atau manipulasi aljabar, akan tetapi berbicara tentang memahami urutan operasi dan aktivitas yang membutuhkan tingkat pemahaman matematis. Literasi matematika lebih banyak melibatkan prosedur pelaksanaan. Ini mengisyaratkan basis pengetahuan dan kompetensi dan kepercayaan diri untuk menerapkan pengetahuan matematika di dunia praktis. Orang yang paham secara matematis dapat memperkirakan, menafsirkan data, memecahkan masalah sehari-hari, memberi alasan dalam situasi numerik, grafik, dan geometris, dan berkomunikasi menggunakan matematika. Sebelum siswa dapat terlibat dalam matematika, mereka perlu memahami kosakata dan dapat "membaca" dan "menulis" menggunakan kosakata itu. Membaca dapat mengambil banyak bentuk sebagai "membaca di kelas matematika seperti siswa melakukan 'decoding' persamaan untuk membaca paragraf dalam buku teks untuk memahami apa masalah yang ditanyakan" (Edelman \& Hutchison, 2014).

Buta matematika, yang merupakan ketidakmampuan untuk menangani angka dan data dengan benar dan untuk mengevaluasi pernyataan mengenai masalah dan situasi yang memerlukan pemrosesan dan estimasi mental, adalah masalah yang lebih besar daripada yang diakui masyarakat (Ojose, 2011). Manifestasi buta huruf (illiteracy) matematika lazim di masyarakat. Salah satu cara untuk menjelaskan masalah ini adalah bahwa konten matematika yang dipelajari di sekolah tidak membuat warga sekolah mahir secara matematis atau 
metode pengajaran konsep tidak membantu warga membuat koneksi ke situasi kehidupan nyata. Untuk mentransfer pengetahuan mereka secara efektif dari satu bidang aplikasi ke bidang lainnya, siswa perlu pengalaman memecahkan masalah dalam banyak situasi dan konteks yang berbeda.

Bagian penting dari literasi matematika adalah menggunakan, melakukan, dan mengenali matematika dalam berbagai situasi. Ketika menyelesaikan masalah-masalah yang memungkinkan siswa untuk memahami aplikasi matematika, pilihan metode dan representasi matematika sering kali tergantung pada situasi dimana masalah tersebut disajikan. Guru matematika sering mengeluh bahwa siswa mengalami kesulitan menerapkan matematika yang telah mereka pelajari dalam konteks yang berbeda. Dalam pembelajaran literasi matematika, siswa akan diberikan kesempatan untuk terlibat dengan masalah-masalah nyata dalam konteks yang berbeda, sehingga mereka dapat mengkonsolidasikan dan memperluas keterampilan matematika dasar. Dengan demikian, literasi matematika akan menghasilkan kemampuan untuk memahami terminologi matematika dan memahami informasi numerik dan spasial yang dikomunikasikan dalam tabel, grafik, diagram, dan teks. Selanjutnya, literasi matematika akan mengembangkan penggunaan keterampilan matematika dasar dalam menganalisis situasi kritis dan secara kreatif memecahkan masalah sehari-hari.

Memiliki dasar pengetahuan tentang kosa kata dan notasi adalah penting. Akan tetapi jika siswa tidak tahu bagaimana bernalar melalui masalah, pengetahuan itu tidak berguna. Tujuan akhir literasi dalam matematika adalah bahwa siswa dapat menggunakan penalaran untuk memecahkan masalah yang kompleks dan kemudian menyajikan jawaban mereka menggunakan bahasa yang benar (Martineau, 2017). Literasi matematika adalah kemampuan untuk melakukan, memahami, dan menerapkan matematika, tidak hanya di ruang kelas, tetapi dalam kehidupan sehari-hari (https://sites.google.com/a/dpi.wi.gov/ disciplinary-literacy-in-mathematics/). De Lange (2006) menyatakan bahwa literasi matematika mencakup literasi spasial, numerasi, dan kuantitatif literasi. Literasi spasial mendukung pemahaman kita tentang dunia (tiga dimensi) tempat kita hidup dan bergerak. Untuk menghadapi apa yang mengelilingi kita, kita harus memahami sifat-sifat benda, posisi relatif benda dan efeknya terhadap persepsi 


\section{Baiduri}

visual kita, penciptaan semua jenis jalur dan rute dua dan tiga dimensi. Numerasi yang menekankan kemampuan untuk menangani angka dan data dan untuk mengevaluasi pernyataan mengenai masalah dan situasi yang mengundang pemrosesan mental dan estimasi dalam konteks dunia nyata. Literasi kuantitatif, literasi berurusan dengan sekelompok kategori fenomenologis: kuantitas, perubahan dan hubungan, dan ketidakpastian. Kategori-kategori ini menekankan pemahaman, dan kemampuan matematika yang berkaitan dengan, kepastian (kuantitas), ketidakpastian (kuantitas serta ketidakpastian), dan hubungan (jenis, perubahan, dan alasan untuk perubahan itu).

Berdasarkan pengertian para ahli, maka literasi matematika mencakup literasi kosa kata dan notasi, literasi spasial, numerasi, dan literasi kuantitatif yang digunakan untuk pemecahan masalah baik dalam matematika sendiri maupun dalam kehidupan dunia nyata. Struktur literasi matematika dapat disajikan secara visual pada Gambar 1. Kapasitas krusial yang tersirat oleh gagasan tentang literasi matematika adalah kemampuan untuk mengajukan, merumuskan, dan memecahkan masalah intra dan ekstra matematika dengan berbagai domain dan situasi. Jika dilihat dari fokusnya, ada perbedaan fokus antara matematika sekolah dan literasi matematika. Matematika di sekolah berfokus pada konten substantif, sedangkan matematika literasi berfokus pada bagaimana menggunakan matematika dalam kehidupan nyata (De Lange, 2003).

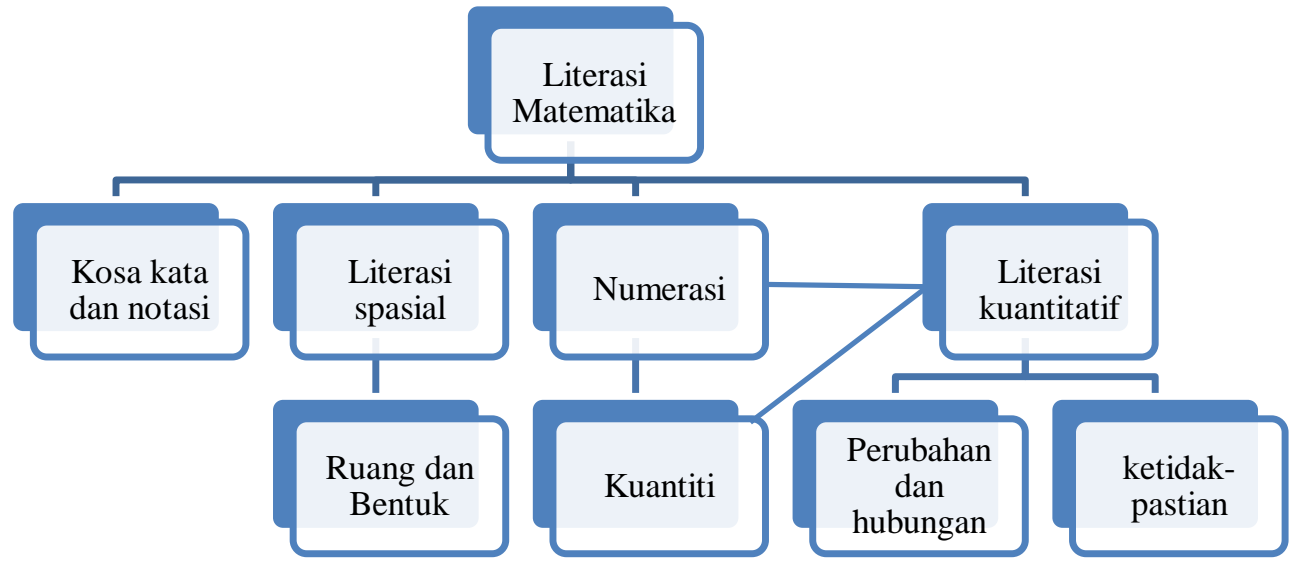

Gambar 1. Struktur Literasi Matematika

Dilihat dari komponennya, literasi matematika terdiri dari dua komponen (Sumirattana, Makanong, \& Thipkong, 2017) yaitu: 1). Pengetahuan, mengacu pada pengetahuan konseptual dan prosedural yang menjadi dasar yang penting 
untuk menghubungkan dan menyelesaikan masalah matematika yang dihadapi dalam kehidupan nyata, dan 2). Kompetensi, mengacu pada kemampuan untuk menerapkan pengetahuan dan keterampilan matematika yang diperoleh dari ruang kelas untuk kehidupan nyata mereka dan untuk memahami situasi melibatkan matematika.

\section{STRATEGI LITERASI DALAM PEMBELAJARAN MATEMATIKA}

Kompetensi yang diperlukan untuk literasi matematika adalah berpikir matematik dan penalaran, berargumentasi secara matematik, berkomunikasi secara matematis, pemodelan, representasi, simbol, alat dan teknologi (OECD, 1999; Steen, 2001). Selain kompetensi ini agar dapat mahir secara matematis, dibutuhkan kepercayaan pada kemampuan sendiri untuk menggunakan matematika dan kenyamanan dengan ide-ide kuantitatif (Ojose, 2011). Siswa dapat dikatakan mahir secara matematis ketika mereka dapat dengan percaya diri dan efektif menggunakan konsep matematika, dan dapat mengenali cara mentransfer keterampilan mereka untuk memecahkan masalah (Storm, Catharines, Marseglia, \& Lapointe, 2010). Siswa yang mahir secara matematis memiliki kemampuan memanfaatkan pengetahuan matematika mereka pada konteks yang berbeda untuk menyelesaikan masalah yang kompleks (Martineau, 2017). Siswa yang mahir secara matematis mampu menganalisis, bernalar, dan mengkomunikasikan ide secara efektif ketika mereka mengajukan, merumuskan, memecahkan, dan menafsirkan masalah matematika dalam berbagai situasi. Departemen Pendidikan Carolina Selatan (2015) dan Reavis (2017) mendefinisikan bahwa siswa yang mahir secara matematis sebagai orang yang dapat: (1) memahami masalah dan bertahan dalam memecahkannya, (2) bernalar baik secara kontekstual maupun abstrak, (3) menggunakan keterampilan berpikir kritis untuk membenarkan penalaran matematika dan kritik penalaran orang lain, (4) menghubungkan ide-ide matematika dan situasi dunia nyata melalui pemodelan, (5) menggunakan berbagai alat matematika secara efektif, (6) berkomunikasi secara matematis dan mendekati situasi matematika dengan presisi, dan (7) mengidentifikasi dan memanfaatkan struktur dan pola. 


\section{Baiduri}

Salah satu cara terbaik untuk memberi siswa latar belakang pengetahuan yang dibutuhkan untuk memahami konsep matematika adalah dengan mengajarkan mereka keterampilan kosakata dan pemahaman, yang sangat penting untuk memahami matematika (Kenney, 2007). Lebih lanjut dinyatakan bahwa strategi yang dapat dilakukan oleh guru di kelas untuk mempersiapkan siswa menjadi pembelajar matematika yang sukses: (1) strategi kosakata, yang membantu siswa memahami istilah-istilah yang penting untuk memahami matematika (Bethany, 2016), (2) strategi membaca-untuk-belajar, yang membekali siswa dengan metode untuk mengekstraksi makna dari teks matematika yang rumit, (3) strategi menulis, yang mempersiapkan siswa untuk pemecahan masalah dan membantu mereka mengenali langkah-langkah dalam proses matematika, (4) representasi grafis, yang membantu siswa memvisualisasikan konsep matematika dan mempersonalisasikan pemahaman mereka (Bethany, 2016) atau dukungan visual (Armstrong, Ming, \& Helf, 2018), dan (5) strategi diskusi dan mendengarkan, yang membantu siswa mengakses pengetahuan sebelumnya dan berkomunikasi tentang pemecahan masalah. Selain itu, Bethany (2016) menggagas penggunaan strategi literasi dalam pembelajaran matematika, yaitu: (1) menggunakan skema (pengetahuan sebelumnya), (2) membuat koneksi, dan (3) membuat prediksi dan kesimpulan.

Strategi (1) sampai (3) pada Kenney (2007) dapat dilakukan dengan model Frayer (Armstrong, Ming, \& Helf, 2018). Model Frayer untuk membangun kosa kata akademik, siswa perlu memahami penggunaan disiplin khusus kosa kata matematika untuk mengajukan pertanyaan, menguraikan dan berinteraksi dengan teks, dan membangun latar belakang pengetahuan. Ketika siswa dapat merumuskan pertanyaan berdasarkan pada kosa kata akademik yang sesuai, mereka lebih mampu untuk berpartisipasi dalam kegiatan seperti diskusi matematika. Siswa juga dapat menavigasi teks dan tidak menjadi putus asa ketika mereka mendekati kata atau konsep baru. Model Frayer khususnya membantu ketika ada kosakata matematika yang juga digunakan di area konten lain dengan cara yang berbeda atau ketika mengajarkan konsep-konsep baru dan sulit. Model Frayer disajikan pada Gambar 2. 


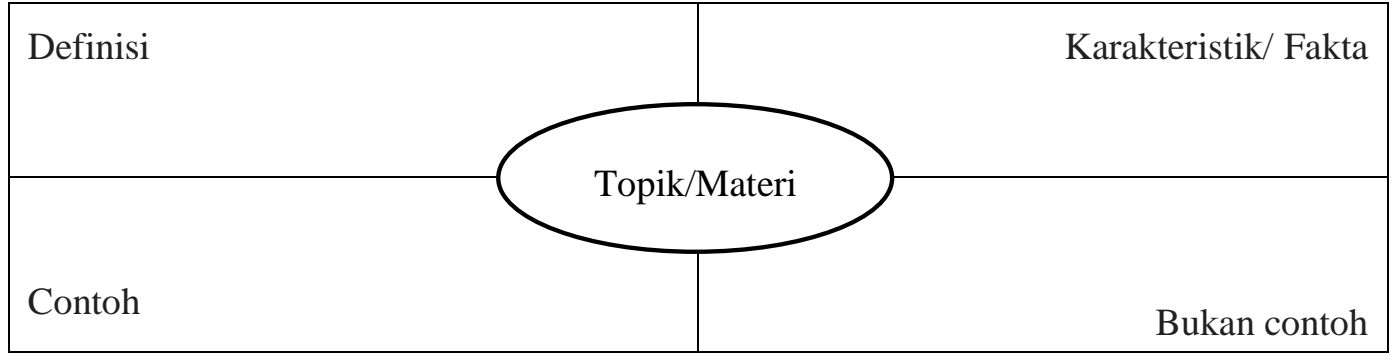

Gambar 2. Model Frayer

Contoh Model Frayer untuk bilangan komposit disajikan pada Gambar 3.

\begin{tabular}{|c|c|}
\hline $\begin{array}{l}\text { Definisi } \\
\text { Seluruh bilangan dengan lebih dari dua } \\
\text { faktor }\end{array}$ & $\begin{array}{l}\text { Karakteristik/ Fakta } \\
\text { - } 4 \text { adalah komposit rendah } \\
\text { - } 0 \text { dan } 1 \text { bukan komposit } \\
\text { - Angka kuadrat memiliki jumlah faktor } \\
\text { ganjil } \\
\text { - } 2 \text { adalah satu-satunya bilangan genap } \\
\text { yang bukan komposit }\end{array}$ \\
\hline $\begin{array}{l}\text { Contoh } \\
4,6,8,9,10,12,14,15,16\end{array}$ & $\begin{array}{r}\text { Bukan contoh } \\
0,1,2,3,5,7,11,13,17\end{array}$ \\
\hline
\end{tabular}

Gambar 3. Model Frayer untuk Bilangan Komposit

Contoh Model Frayer untuk fungsi kuadrat disajikan pada Gambar 4.

\begin{tabular}{|l|l|r|}
\hline Definisi buku & \\
\hline Contoh & & Definisi saya \\
\hline $\begin{array}{l}\text { Diberikan sebuah fungsi kuadrat, } \\
\text { gambarkan sketsa grafiknya! }\end{array}$ & $\begin{array}{l}\text { Diberikan sebuah grafik, tentukan } \\
\text { fungsinya! }\end{array}$ \\
\hline Tulislah deskripsi gambar parabola yang anda gambarkan dikaitkan dalam dunia nyata! \\
\hline
\end{tabular}

\section{Gambar 4. Model Frayer untuk Fungsi Kuadrat}

Strategi dengan skema. Ketika merencanakan pelajaran matematika, akan sangat membantu bagi siswa jika dimulai dengan yang sudah siswa kenal dan berupaya membangun jembatan ke konten baru. Pada saat siswa mempelajari 


\section{Baiduri}

konsep yang baru, siswa akan mengalami ketidakseimbangan pada kognisinya. Untuk mengatasi ketidakseimbangan ini dilakukan melalui proses asimilasi atau akomodasi. Hal ini juga akan membantu siswa dalam memecahkan masalah. Ketika mereka melihat masalah matematika, mintalah mereka bertanya pada diri sendiri, “Apa yang saya tahu?", kemudian menuliskannya. Cari hal-hal yang umum (seperti kosakata yang dikenal) dan lihat apakah itu memberikan wawasan tentang bagaimana menyelesaikan masalah. Metode populer dalam membaca instruksi adalah dengan menggunakan bagan KWL (What do I Know, what do I Want to know, and then what did I Learn). Ini dapat dengan mudah digunakan ketika mempelajari konsep matematika baru dan membantu anak-anak membuat koneksi. Metode KWL dapat disajikan seperti Gambar 5.

\begin{tabular}{|c|c|}
\hline Topik & $\begin{array}{l}\text { Seorang akan menukarkan uang Rp } 50.000 \text { dengan } \\
\text { pecahan Rp } 10.000 \text { dan Rp } 5.000 \text {. Berapa banyak } \\
\text { pecahan Rp } 10.000 \text { dan Rp } 5.000 \text { yang mungkin } \\
\text { didapat? }\end{array}$ \\
\hline $\begin{array}{c}\text { APA YANG SAYA } \\
\text { KETAHUI }\end{array}$ & $\begin{array}{l}\text { APA YANG INGIN } \\
\text { SAYA KETAHUI }\end{array}$ \\
\hline
\end{tabular}

\section{Gambar 5. Model KWL}

Strategi membuat koneksi. Strategi ini membantu siswa/anak menggunakan pengetahuan mereka sebelumnya memberi mereka sesuatu untuk menghubungkan konsep baru. Tetapi siswa dapat membuat koneksi dengan cara lain juga, dan ini adalah strategi yang sangat berguna untuk membantu mereka belajar, menerapkan dan mengingat konsep matematika baru. Jenis koneksi matematika: matematika ke ilmu lain, matematika untuk diri sendiri, dan matematika ke dunia nyata. Semua matematika saling terkait, dan penting untuk membantu anak-anak melihat hubungan antara satu konsep matematika dengan yang lainnya. Kemudian, harus ditemukan cara untuk membuat hubungan antara matematika yang dipelajari dengan kehidupan, dan membantu anak melihat matematika di dunia sekitar. Proses menyelesaikan masalah ekstra matematika atau dunia nyata membutuhkan keterampilan dan kompetensi yang diperoleh melalui sekolah dan pengalaman hidup. Peran mendasar dalam proses itu disebut sebagai 'matematikasisasi'. Proses matematikasisasi terbagi menjadi dua bagian 
besar. Proses pertama menstranformasi dunia nyata ke dunia matematika (memformulasi) yang dimulai dengan (1) masalah yang terletak pada “kenyataan". (2) selanjutnya pemecah masalah mencoba mengidentifikasi matematika yang relevan, (3) mengatur kembali masalah sesuai dengan konsep matematika yang diidentifikasi diikuti dengan secara bertahap mengeliminir masalah nyata menjadi masalah matematika. Proses kedua bekerja dalam matematika, yaitu (4) menyelesaikan masalah matematika, dan (5) menginterpretasi solusi matematis ke dalam solusi dunia nyata. Gambar 6 menunjukkan karakter siklik dari proses matematikasisasi.

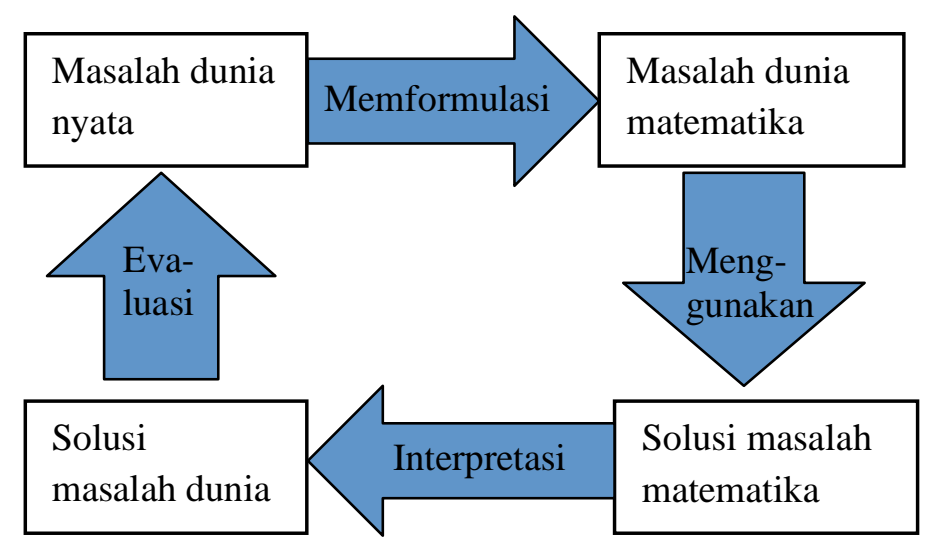

Gambar 6. Siklus Matematikasisasi

Kemampuan untuk merumuskan, menggunakan, dan menafsirkan matematika dalam berbagai konteks, termasuk penalaran matematis dan menggunakan konsep, prosedur, fakta dan alat matematika untuk menggambarkan, menjelaskan dan memprediksi fenomena merupakan literasi matematika (PISA, 2015). Sebagai contoh untuk kasus koneksi matematika dengan dunia nyata adalah Masalah Batu Taman (Tim Boudreau, 2015).

Strategi membuat prediksi dan kesimpulan. Strategi ini sangat penting untuk memahami apa yang dibaca sehingga perlu diadaptasi untuk pembelajaran matematika. Siswa perlu tahu bahwa membuat prediksi yang kemudian terbukti atau tidak terbukti adalah proses yang telah digunakan oleh ahli matematika. Memiliki ide tentang bagaimana menyelesaikan masalah, kemudian melihat bahwa itu adalah metode yang valid atau tidak adalah hal yang dilakukan sebagai ahli matematika. Ini adalah inti dari proses pemecahan masalah. Strategi ini akan 


\section{Baiduri}

terbantu jika didukung oleh strategi membuat visualisasi. Memvisualisasikan dan menggambar adalah strategi membantu siswa memberikan gambaran mental yang akan membantu mereka mengingat apa yang telah dipelajari. Ini juga dapat membantu memecahkan masalah menjadi bagian-bagian yang lebih mudah dipahami. Visualisasi dapat dibantu dengan menggunakan software aplikasi, misalnya Geogebra.

Sebagai contoh masalah adalah

1. Ada sekitar 6 juta orang di Surabaya. Berapa guru sekolah yang ada?

Untuk menyelesaikan masalah ini (membuat prediksi secara rasional) adalah memformulasi masalah matematika dengan cara menentukan variabel yang penting, serta membuat asumsi-asumsi.

$\begin{array}{ll}\text { Jumlah populasi (p) } & \mathbf{6 . 0 0 0 . 0 0 0} \\ \text { Lama sekolah (dasar dan menengah) (t) } & 12 \text { tahun } \\ \text { Rata-rata umur (n) } & 80 \text { tahun } \\ \text { Ukuran kelas (c) } & 25 \text { siswa } \\ \text { Hubungan dan Fakta } & \text { Prediksi } \\ \text { Rasio populasi yang sekolah, t:n } & 1 / 7 \\ \text { Populasi yang sekolah, } p^{*}(\mathrm{t}: \mathrm{n}) & 850.000 \\ \text { Jumlah guru, } \mathrm{p}^{*}(\mathrm{t}: \mathrm{n}): \mathrm{c} & 34.000\end{array}$

2. Anda akan membuat kandang kelinci berbentuk persegi panjang. Anda telah memutuskan untuk membangun kandang menggunakan bagian belakang rumah Anda sebagai satu sisi kandang dan tiga sisi lainnya dengan pagar panjang. Jika Anda ingin memiliki ruang sebanyak mungkin, berapa panjang dan lebar kandang? Pertimbangkan, 1. Bisakah Anda memiliki 2 persegi panjang yang memiliki perimeter yang sama tetapi area yang berbeda? 2 . Bisakah Anda memiliki 2 persegi panjang dengan area yang sama tetapi batas yang berbeda? 3. Bisakah Anda menentukan keliling persegi panjang jika area tersebut diketahui? 4. Bisakah Anda menentukan luas persegi panjang jika batasnya diketahui? (Smith dkk, 2005).

3. Sebuah ruangan berbentuk balok dengan panjang 6,5 meter, lebar 4,5 meter, dan tinggi 2,33 meter, akan diisi dengan kubus dan bola. 
a. Sebuah blok besar yang telah dibuat berbentuk kubus $10 \times 10 \times 10$ dari 1000 kubus kecil dengan sisi $2 \mathrm{~cm}$. Lingkari angka yang sangat dekat dengan jumlah blok besar yang diperlukan untuk mengisi ruangan ini
$100 \quad 1.000$
10.000
100.000
1.000 .000

Tentukan seakurat mungkin berapa banyak blok besar yang dibutuhkan untuk mengisi ruangan ini? Jelaskan metode Anda!

b. Lingkari angka yang sangat dekat dengan jumlah bola tenis besar yang diperlukan untuk mengisi ruangan ini (asumsi diameter bola tenis $25 \mathrm{~cm}$ )
100
1.000
10.000
100.000
1.000 .000

Tentukan seakurat mungkin berapa banyak bola tenis yang dibutuhkan untuk mengisi ruangan ini? Jelaskan metode Anda! (Smith dkk, 2005).

\section{SIMPULAN}

Meskipun mempelajari bahasa matematika yang tepat itu sulit, dan terkadang membosankan, itu bisa sangat bermanfaat. Mahasiswa perlu belajar berkomunikasi seperti ahli matematika profesional karena literasi menyiratkan kemampuan terintegrasi untuk berfungsi secara baik dalam komunitas praktik tertentu (De Lange, 2003). Setelah lulus kuliah, diharapkan mahasiswa dapat memahami bagaimana "membaca" dan "menulis" menggunakan kosa kata matematika, notasi, dan cara-cara merepresentasikan data yang sesuai dengan konteksnya serta memiliki kemampuan berkomunikasi dengan benar dengan ahli matematika profesional di perguruan tinggi (pasca sarjana) atau dalam karier. Mahasiswa dapat menggunakan penalaran dan argumen matematis untuk menyelesaikan masalah dan menyajikan solusi menggunakan bahasa yang tepat dengan cara yang bisa dipahami oleh ahli matematika manapun (Martineau, 2017). Agar dapat memanfaat kehadiran era industri 4.0 atau mengantisipasi masa yang akan datang, mahir secara matematika sangat diperlukan. Strategi literasi dapat diterapkan dalam proses pembelajaran untuk mencapai kecakapan matematika, antara lain strategi kosakata dan notasi, skema, membuat koneksi, membuat prediksi dan kesimpulan, dan membuat visual. Strategi-strategi tidak berdiri sendiri dan akan menjadi lebih baik jika didukung dengan penggunaan teknologi yang tepat. 


\section{DAFTAR PUSTAKA}

Armstrong, A., Ming, K., \& Helf, S. (2018). Content Area Literacy in the Mathematics Calssroom. The Clearing House: A Journal of Education Strategies, Issues and Ideas, 91(2), 1-11.

Atif, K. (2013). Mathematical Literacy: A Necessary Skill for the $21^{\text {st }}$ Century. Retrieved from https://blogs.plos.org/scied/2013/02/11/mathematicalliteracy-a-necessary-skill-for-the-21st-century/.

Bethany (2016). Using Literacy Strategies to Teach Math. Retrieved from https://mathgeekmama.com/using-literacy-strategies-to-teach-math/

Borsecnik, L., \& Holzhuter, K. (2015). Mathematical Literacy and the Standards for Mathematical Practice. Retrieved from http://www.wismath.org/ Resources/Documents/Annual\%20Conference/113Lborsecnik-Connecting \%20Math \%20Practice\%20Standards\%20PP.pdf.

Brown-Martin, G. (2017). Education and the Fourth Industrial Revolution. Toronto: Groupe Média TFO.

Department of Education (2003). National Curriculum Statement Grades 10-12 (General); Mathematical Literacy, South Africa.

De Lange, J. (2003). Mathematic for Literacy in B. L. Madison \& L. A. Steen (Eds.), Quantitative Literacy: Why Numeracy Matters for Schools and Colleges (pp. 75-89). United States: Woodrow Wilson Natl Foundation.

De Lange, J. (2006). Mathematical Literacy for Living from OECD-PISA Perspective. Tsukuba Journal of Educational Study in Mathematics, 25, 13-35.

Devlin, K. (2000). The four faces of mathematics. Retrieved from https://www.re searchgate.net/publication/265740772_The_Four_Faces_of_Mathematics.

Edelman, J., \& Hutchison, L. (2014). Literacy in the Mathematics Classroom in Teaching Dilemmas and Solutions in Content-Area Literacy, Grades 6-12 (pp. 81-102). Thousand Oaks, CA: Corwin.

Fang, Z., \& Coatoam, S. (2013). Disciplinary Literacy: What You Want to Know About It. Journal of Adolescent \& Adult Literacy, 56(8), 627-632.

Hermann, M., Pentek, T., \& Otto, B. (2015). Design Principles for Industry 4.0 Scenarios: A Literature Review. Retrieved from http://www.iim.mb.tudortmu nd.de/cms/de/forschung/Arbeitsberichte/Design-Principles-forIndustrie-4_0-Scenarios.pdf.

Hynd-Shanahan, C. (2013). What does It Take? The Challenge of Disciplinary Literacy. Journal of Adolescent \& Adult Literacy, 57(2), 93-98.

Ippolito, J., Dobbs, C. L., \& Charner-Laird, M. (2017). What Literacy Means In Math Class. The Learning Professional, 38(2), 66-70.

Kenney, J. M. (2007). Literacy Strategies for Improving Mathematics Instruction. Heatherton, Vic: Hawker Brownlow Education.

Mulyani, S. (2018). Matematika Diperlukan dalam Menghadapi Revolusi Industri 4.0. Retrieved from https://kumparan.com/bandungkiwari/sri-mulyanimatematika-diperlukan-dalam-menghadapi-revolusi-industri-4-01538271015315718945.

Marr, B. (2016). What Everyone Must Know About Industry 4.0. Retrieved from https://www.forbes.com/sites/bernardmarr/2016/06/20/what-everyonemust-know-about-industry-4-0/. 
Martin (2017). Industry 4.0: Definition, Design Principles, Challenges, and the Future of Employment. Retrieved from https://www.cleverism.com/industry-4-0/.

Martineau, C. (2017). What is Mathematical Literacy. Retrieved from https://medium.com/literate-schools/what-is-mathematical-literacy$65775 \mathrm{f} 3 \mathrm{e} 5 \mathrm{ce} 3$.

Moore, M. (2018). What is Industry 4.0? Everything you need to know. Retrieved from https://www.techradar.com/news/what-is-industry-40-everythingyou-need-to-know.

OECD (1999). Measuring student knowledge and skills: A new framework for assessment. Paris: OECD.

OECD (2006). Assessing Scientific, Reading and Mathematical Literacy: A Framework for PISA 2006. Retrieved from http://www.oecd.org/pisa/pisapro ducts/pisa2006/37464175.pdf.

Ojose, B. (2011). Mathematics Literacy: Are We Able To Put The Mathematics We Learn Into Everyday Use? Journal of Mathematics Education, 4(1), 89-100.

PISA (2015). PISA Results in focus. Retrieved from https://www.oecd.org/ pisa/pisa-2015-results-in-focus.pdf.

Reavis, L. (2017). Literacy in the mathematics classroom. Retrieved from https://medium.com/literate-schools/literacy-in-the-mathematicsclassroom-e9 7c9a2979d7.

Shanahan, C. (2012). How disciplinary experts read in T. Jetton \& C. Shanahan (Eds.) Adolescent literacy in the academic disciplines: General principles and practical strategies (pp. 6990). New York, NY: Guilford.

Shanahan, C., \& Shanahan, T. (2014). The implications of disciplinary literacy. Journal of Adolescent \& Adult Literacy, 57(8), 628-631.

Smith, M. S., Silver, E. A., Stein, M. K., Henningsen, M. A.,Boston, M., \& Hughes, E. K. (2005) Improving Instruction in Geometry: Using Cases to Transform Mathematics Teaching and Learning, Volume 3. New York: Teachers College, Columbia University.

Steen, L. A. (2001). Mathematics and Democracy: The Case for Quantitative Literacy. Princeton, NJ: National Council on Education and the Disciplines.

Steen, L. A., Turner, R., \& Burkhardt, H. (2007). Developing Mathematicalliteracy. Modelling and Applications in Mathematics Education: The $14^{\text {th }}$ ICMI Study, 10, 285-294.

Storm, J., Catharines, S., Marseglia, A., \& Lapointe, D. (2010). What Does Math Literacy Mean? Retrieved from https://www.oxfordlearning.com/WhatDoes-math-literacy-mean/.

Sumirattana, S., Makanong, A., \& Thipkong, S. (2017). Using Realistic Mathematics Education and the DAPIC Problem-Solving Process to Enhance Secondary School Student's Mathematical Literacy. Kasetsart Journal of Social Sciences, 38, 307-315.

TFO (2017). An Emergency for the World of Education: Adapting to the Digital Revolution. Groupe Média.

Toffler, A. (1970). Future Shock. États-Unis: Bantam Books. 
UNESCO (2004). The Plurality of Literacy and its implications for Policies and Programs . UNESCO Education Sector Position Paper, 13.

Vithal, R., \& Bishop, A. J. (2006). Mathematical Literacy: A New Literacy or A New Mathematics? Pythagoras, 64, 2-5.

Watson, A. (2002). Teaching for understanding in L. Haggarty (Ed.), Aspects of Teaching Secondary Mathematics: Perspectives on Practice (pp.153-162). London, UK: Routledge Falmer.

World Economic Forum (2016). The 10 skills you need to thrive in the Fourth Industrial Revolution. Retrieved from https://www.weforum.org/ agenda/2016/01/the-10-skills-you-need-to-thrive-in-the-fourthindustrialrevo lution/ 